\title{
Herança da resistência à ferrugem da folha da aveia (Puccinia coronata f. sp. avenae Fraser \& Led.) em genótipos brasileiros de aveia branca
}

\author{
Inheritance of oat leaf rust (Puccinia coronata f. sp. avenae Fraser \& Led.) resistance \\ in white oat brazilian genotypes \\ Eduardo Alano Vieira ${ }^{1}$ Fernando Irajá Félix de Carvalho ${ }^{1}$ Márcia Soares Chaves ${ }^{2}$ \\ Antonio Costa de Oliveira ${ }^{1}$ José Antônio Gonzalez da Silva ${ }^{1}$ Ivandro Bertan ${ }^{1}$ \\ Douglas André Mallman Schmidt ${ }^{1}$ Guilherme Ribeiro ${ }^{1}$ \\ Taciane Finatto $^{1}$ Gustavo da Silveira ${ }^{1}$
}

\section{RESUMO}

A ferrugem da folha da aveia é a moléstia mais importante que ataca a cultura da aveia, ocorrendo em praticamente todas as áreas em que a aveia é cultivada. A forma mais indicada para o seu controle é a utilização de cultivares resistentes. Contudo para que seja alcançada a resistência durável ao patógeno, é necessário que se conheça a genética da resistência à ferrugem da folha em aveia. $O$ objetivo foi determinar a forma de herança da resistência a três isolados de Puccinia coronata f. sp. avenae Fraser \& Led., (coletados no sul do Brasil) em genótipos brasileiros de aveia branca. Para a determinação da herança da resistência a cada um dos três isolados, foram utilizadas populações $F_{2}$ geradas por meio de cruzamentos artificiais, entre genótipos resistentes $(R)$ e suscetíveis $(S)$ e entre genótipos resistentes $(R)$. Desta forma, foram utilizadas populações $F_{2}$ dos cruzamentos artificiais entre: i) URPEL 15 (R) x UFRGS 7 (S), UPF $16(R)$ $x$ UFRGS 7 (S) e URPEL 15 (R) x UPF $16(R)$, para a determinação da herança da resistência ao isolado um (1); ii) URPEL 15 (R) x UFRGS 7 (S), UPF 18 (R) x UFRGS 7 (S) e URPEL $15(R)$ x UPF $18(R)$, para a determinação da herança da resistência ao isolado dois (2); iii) URPEL 15 (R) $x$ UFRGS $7(S)$ e URPEL 15 (R) x UPF $18(S)$, para a determinação da herança da resistência ao isolado três (3). Os resultados obtidos evidenciaram que o genótipo URPEL 15 apresenta genes dominantes de resistência aos três isolados de ferrugem da folha da aveia avaliados, que o cultivar UPF 16 apresenta um gene recessivo de resistencia ao isolado 1 e o cultivar UPF 18 apresenta um gene recessivo de resistência ao isolado 2. E que os genes de resistência apresentados pelos genótipos URPEL 15, UPF 16 e UPF 18, segregam de forma independente.

Palavras-chave: Avena sativa; ferrugem da folha da aveia; genética da resistência, melhoramento genético.

\section{ABSTRACT}

Oat crown rust is the most important disease for the oat crop, occurring in practically all the areas where oat is cultivated. The most indicated form of control for this disease is the use of resistant cultivars. However, for the durable resistance to be acquired, it is necessary to know the genetics of resistance to crown rust in oats. Thus, the objective of this work was to determine the type of inheritance of resistance to three Puccinia coronata $f$. sp. avenae Fraser \& Led., isolates (collected in southern Brazil) in brazilian white oat genotypes. To determine the inheritance of resistance to each one of three isolates, $F_{2}$ populations were used generated through artificial crosses, between resistant $(R)$ and susceptible $(S)$ and between resistant genotypes $(R)$. Thus, $F_{2}$ populations from the following artificial crosses: i) URPEL 15 (R) $x$ UFRGS 7 (S), UPF 16 (R) x UFRGS 7 (S) and URPEL 15 (R) $x U P F$ $16(R)$, were used to determine the inheritance of resistance to isolate one (1); ii) URPEL 15 (R) $x$ UFRGS 7 (S), UPF 18 (R) $x$ UFRGS 7 (S) and URPEL 15 (R) $x$ UPF $18(R)$, to determine the inheritance of resistance to isolate two (2); iii) URPEL 15 (R) $x$ UFRGS 7 (S) and URPEL 15 (R) $x$ $U P F 18(S)$, to determine the inheritance of resistance to isolate three (3). The obtained results indicate that the genotype URPEL 15 present dominants genes for resistance to the three oat leaf rust isolates evaluated, the cultivar $U P F 16$ presents a recessive gene for resistance to isolate 1 and the cultivar UPF 18 has a recessive gene of resistence to isolate 2. Also, the resistance genes presented by genotypes URPEL 15, UPF 16 and UPF 18, segregate in an independent manner.

Key words: Avena sativa; oat crown rust; genetic resistance, plant breeding.

${ }^{1}$ Universidade Federal de Pelotas (UFPel) - Faculdade de Agronomia "Eliseu Maciel" (FAEM)/Centro de Genômica e Fitomelhoramento. CP. 354, CEP. 96010-900, Pelotas, RS, Brasil. E-mail: carvalho@ufpel.tche.br Autor para correspondência. ${ }^{2}$ Embrapa Trigo, Passo Fundo, RS, Brasil. 


\section{INTRODUÇÃO}

A ferrugem da folha da aveia, causada pelo fungo (Puccinia coronata f. sp. avenae Fraser \& Led.,), é a moléstia mais importante que ataca a cultura da aveia, ocorrendo em praticamente todas as áreas em que a aveia é cultivada (SIMONS \& MURPHY, 1961). A moléstia vem sendo apontada como um dos principais fatores limitantes para a expansão da área cultivada com o cereal, uma vez que a mesma pode ocasionar perdas no rendimento, por reduzir o peso e a qualidade dos grãos, mesmo em plantas moderadamente atacadas (DOEHLERT et al., 2001; LORENCETTI et al., 2004; BENIN et al., 2005).

As formas mais empregadas para o controle do fungo são a utilização de fungicidas e de variedades resistentes. O uso de variedades resistentes é considerado a opção mais barata e ambientalmente favorável, uma vez que o emprego de produtos químicos eleva os custos de produção e pode trazer sérios danos ao ambiente e à saúde dos trabalhadores rurais. Entretanto, apesar da resistência genética ser apontada como a forma mais eficiente para o controle da moléstia, a mesma apresenta o inconveniente da baixa durabilidade, principalmente em função do curto período de tempo em que os genótipos permanecem efetivos no controle do patógeno (CHONG \& KOLMER, 1993; KOLMER \& CHONG, 1993). Em especial, a resistência determinada por um ou poucos genes pode ser rapidamente superada por novas raças do patógeno que aumentam de freqüência devido à grande pressão de seleção exercida pelo cultivo sob grandes áreas de genótipos uniformes para a resistência ao patógeno. Essas surgem por meio de mutações ou, por meio de correntes de ar que, chegam de outros locais (HARDER \& HABER, 1992). No processo evolutivo, o aparecimento de novas raças em populações da ferrugem da folha pode ocorrer principalmente via a acumulação de mutações em populações assexuais ou por recombinação sexual no hospedeiro alternativo (Rhamnus cathartica L.), o qual ocorre naturalmente na América do Norte (CHONG \& KOLMER, 1993).

No sul do Brasil, vários fatores os quais atuam de forma conjunta ou isoladamente, contribuem para que haja uma elevada variabilidade para virulência nas populações do fungo: i) o patógeno evidencia uma taxa de mutação elevada, em torno de um esporo mutante a cada 2000 esporos produzidos (ZIMMER et al., 1963); ii) o cereal é cultivado durante todos os meses do ano na região do Cone Sul, sem barreiras físicas que impeçam a disseminação rápida de qualquer esporo mutante via vento (BROWN \& HOVMOLLER, 2002); iii) existem outras gramíneas que oferecem oportunidade para a infecção e produção de inóculo, além de requererem genes adicionais de virulência; iv) as condições de ambiente proporcionam um longo período de infecção e esporulação, o que aumenta o número de ciclos de infecção do patógeno e conseqüentemente a quantidade de inóculo produzida (FEDERIZZI \& STUTHMAN, 1998). Desta forma, os genes de resistência incorporados às constituições genéticas brasileiras, vêm sendo rapidamente superados pelo patógeno, o que faz com que atualmente, nenhum dos cultivares recomendados para o cultivo, no Brasil seja imune à moléstia .

A resistência pode ser definida como a habilidade do hospedeiro em impedir o crescimento e o desenvolvimento do patógeno (PARLEVLIET, 1997). Segundo FLOR (1956), a reação de resistência é o efeito da interação entre o produto do gene de resistência do hospedeiro (normalmente dominante) e o produto do gene de avirulência do patógeno (normalmente dominante). A resistência a moléstias de plantas pode ser obtida por meio da incorporação de um, de poucos ou de vários genes de resistência em um genótipo (AGRIOS, 1988). Contudo para que seja alcançada a resistência durável ao patógeno, é necessário que se conheça profundamente a variabilidade para virulência das populações do patógeno e a genética da resistência à ferrugem da folha em aveia. $\mathrm{O}$ conhecimento da forma da herança da resistência é fundamental para o melhoramento genético, porque essa ajuda a definir qual o método de melhoramento mais apropriado para a transferência deste caráter de um indivíduo a outro.

O objetivo foi determinar a forma de herança da resistência a três isolados de Puccinia coronata f. sp.avenae Fraser \& Led., (coletados no sul do Brasil) em genótipos brasileiros de aveia branca.

\section{MATERIAL E MÉTODOS}

No presente trabalho, foram utilizados, três isolados do fungo Puccinia coronata f. sp. avenae Fraser \& Led., com seus padrões de virulência/avirulência a 25 genes $P c$ s $(40,45,46,50,38,39,48,68,51,52,58,59,54,56$, $62,64,14,35,36,53,55,57,60,61$ e 63$)$, locais de coleta e cultivares sob os quais foram coletados, determinados por Vieira (2005; Tabela 1). Os isolados foram escolhidos em função de evidenciarem número diferenciado de genes de virulência aos 25 Pcs listados acima, isolado 1 (16 genes), isolado 2 (21 genes) e isolado 3 (12 genes; Tabela 1), além de possuírem seu padrão de virulência/avirulência em relação aos genótipos URPEL 15, UPF 16, UPF 18 e UFRGS 7, conhecido (Tabela 2). 
Para a determinação da herança da resistência a cada um dos três isolados, foram utilizadas populações $F_{2}$ geradas por meio de cruzamentos artificiais, entre genótipos resistentes $(\mathrm{R})$ e suscetíveis (S) e entre genótipos resistentes (R). Desta forma, foram utilizadas populações $F_{2}$ dos cruzamentos artificiais entre: i) URPEL 15 (R) x UFRGS 7 (S), UPF 16 (R) x UFRGS 7 (S) e URPEL 15 (R) x UPF 16 (R), com respectivamente, 303, 323 e 272 indivíduos, para a determinação da herança da resistência ao isolado um (1);ii) URPEL 15 (R) x UFRGS 7 (S), UPF 18(R) x UFRGS 7 (S) e URPEL 15 (R) x UPF 18 (R), com respectivamente, 311, 297 e 305 indivíduos, para a determinação da herança da resistência ao isolado dois (2); iii) URPEL 15 (R) x UFRGS 7 (S) e URPEL 15 (R) x UPF 18 (S), com respectivamente, 241 e 295 indivíduos, para a determinação da herança da resistência ao isolado três (3).

Esporos de cada um dos três isolados foram suspensos em água, na concentração de $10^{5}$ esporos $\mathrm{mL}^{-1}$, e aspergidos sobre plântulas $\mathrm{F}_{2}$ dos cruzamentos e dos genitores empregados no estudo, com a primeira folha completamente expandida (sete dias após a semeadura). Da mesma maneira que as populações segregantes e os genitores foram inoculados também, plântulas de 25 linhagens quase isogênicas contendo os genes $P$ cs (40, 45, 46, 50, 38, 39, 48, 68, 51, 52, 58, 59 , $54,56,62,64,14,35,36,53,55,57,60,61$ e 63 ), para confirmar o padrão de virulência/avirulência a tais genes nos isolados e assim evitar eventuais problemas oriundos de contaminações. Antes da inoculação, todas as plântulas foram aspergidas com água contendo Tween 20 na concentração de $10 \mathrm{~mL} 100 \mathrm{~mL}^{-1}$ e após a inoculação foram mantidas em câmara úmida, no escuro, por $18 \mathrm{~h}$ a temperatura de $20-24^{\circ} \mathrm{C}$ e umidade de $95 \%$, para garantir a germinação dos esporos. Após este período, as plântulas foram transferidas para casa de vegetação com condições semicontroladas. Quinze dias após a inoculação dos genótipos, foi efetuada a avaliação dos resultados. A distinção entre alto (virulência) e baixo (avirulência) o tipo de infecção foi realizada com base no critério descrito por $\mathrm{CHONG}$ et al. (2000). Foi empregada uma escala quantitativa composta de notas variando de 0 a 4 onde: $(0)=$ ausência urédia ou outros sinais macroscópicos de infecção, (;) = presença de reação marcante de hipersensibilidade sem esporulação, $(1)=$ pequena urédia rodeada por clorose ou necrose, $(2)=$ urédia de tamanho variando de pequeno a médio rodeada por clorose, (3) = urédia de tamanho médio em área clorótica e (4) = grande urédia sem clorose ou necrose. As notas (0), (;), (1) e (2), foram consideradas como indicativo de resistência do hospedeiro (baixo tipo de infecção e as notas (3) e (4), foram consideradas como indicativo de suscetibilidade do hospedeiro (alto tipo de infecção).

A determinação do ajuste entre as frequências observadas e as esperadas, segundo as hipóteses levantadas no estudo, foram efetuadas por meio do teste do qui-quadrado $\left(\chi^{2}\right)$ a $5 \%$ de probabilidade de erro.

\section{RESULTADOS E DISCUSSÃO}

A inoculação dos três isolados sobre os 25 genes $P c s(40,45,46,50,38,39,48,68,51,52,58,59,54$, $56,62,64,14,35,36,53,55,57,60,61$ e 63$)$, que foi realizada juntamente com a inoculação das plântulas $\mathrm{F}_{2}$ dos cruzamentos e dos genitores, revelou a pureza dos isolados, uma vez que os mesmos evidenciaram o mesmo padrão de virulência/avirulência que havia sido determinado anteriormente por VIEIRA (2005), padrão este que esta apresentado na Tabela 1. Ou seja, o isolado 1 foi virulento aos $P$ cs $(40,45,46,39,51,58,59$, $54,64,36,53,55,35,57,60$ e 61) e avirulento aos $P c$ s ( $50,38,48,68,52,62,56,14$ e 63 ), o isolado 2 foi virulento aos $P$ cs $(40,45,46,50,38,39,51,58,59,54,56,62,64,36$, $55,63,14,35,57,60$ e 61$)$ e avirulento aos $P c$ s $(48,68,52$ e 53) enquanto que o isolado 3 foi virulento aos $P c s$ $(40,45,46,48,51,52,58,59,56,36,53$ e 61$)$ e a avirulento $(50,38,39,68,54,62,64,14,35,55,57,60$ e 63$)$. Tais resultados são importantes por evidenciarem a eficiência dos processos de multiplicação e de inoculação dos isolados sobre as plântulas estudadas (Pcs, genitores e populações $\mathrm{F}_{2}$ ).

Os resultados obtidos por meio da inoculação do isolado 1 sobre as plântulas $F_{2}$ dos cruzamentos URPEL 15 (R) x UFRGS 7 (S), UPF 16(R) x UFRGS 7 (S) e URPEL 15 (R) x UPF 16 (R) estão apresentados na Tabela 3. Tais resultados revelaram que a resistência do genótipo URPEL 15 ao isolado 1 é

Tabela 1- Relação dos isolados utilizados no estudo com a indicação dos locais de coleta, cultivares dos quais foram coletados e genes $P c$ s aos quais são virulentos dentre os 25 Pcs empregados no estudo. FAEM/UFPel, 2005.

\begin{tabular}{clll}
\hline Isolado & Origem do isolado & Cultivar & Genes de virulência presentes \\
\hline 1 & Passo Fundo (PF) & UPFA 20 & $40,45,46,39,51,58,59,54,64,36,53,55,35,57,60$ e 61. \\
2 & Capão do Leão (CL) & UPFA 20 & $40,45,46,50,38,39,51,58,59,54,56,62,64,36,55,63,14,35,57,60$ e 61. \\
3 & Capão do Leão (CL) & ALBASUL & $40,45,46,48,51,52,58,59,56,36,53$ e 61. \\
\hline
\end{tabular}

Ciência Rural, v.36, n.1, jan-fev, 2006. 
Tabela 2- Padrão de virulência (alto tipo de infecção; A) e avirulência (baixo tipo de infecção; B) e prováveis constituições genéticas para a resistência de três isolados de Puccinia coronata f. sp. avenae a quatro genótipos de aveia. FAEM/UFPel, 2005.

\begin{tabular}{|c|c|c|c|c|c|}
\hline \multirow{2}{*}{ Genótipo } & \multicolumn{3}{|c|}{ Isolado } & \multirow{2}{*}{ (possíveis genes de resistência) } & \multirow{2}{*}{$\begin{array}{c}\text { Isolado (possíveis genes de virulência) } \\
1(\mathrm{AAbb})\end{array}$} \\
\hline & 1 & 2 & 3 & & \\
\hline URPEL 15 & $\mathrm{~B}$ & $\mathrm{~B}$ & B & $(\mathrm{AABB})$ & $\mathrm{R}$ \\
\hline UPF 16 & $\mathrm{~B}$ & A & A & (aabb) & $\mathrm{R}$ \\
\hline \multirow[t]{2}{*}{ UFRGS 7} & A & A & A & $(\mathrm{aaBB})$ & S \\
\hline & & & & & $2(\mathrm{AAbb})$ \\
\hline URPEL 15 & B & B & B & $(\mathrm{AABB})$ & $\mathrm{R}$ \\
\hline UPF 18 & A & B & A & $(a a b b)$ & $\mathrm{R}$ \\
\hline \multirow[t]{2}{*}{ UFRGS 7} & A & A & A & $(\mathrm{aaBB})$ & S \\
\hline & & & & & $3(\mathrm{AABB})$ \\
\hline URPEL 15 & B & $\mathrm{B}$ & B & $(\mathrm{AABB})$ & $\mathrm{R}$ \\
\hline UPF 18 & A & B & A & (aabb) & S \\
\hline UFRGS 7 & A & A & A & (aabb) & $\mathrm{S}$ \\
\hline
\end{tabular}

determinada por apenas um gene dominante, uma vez que a população $F_{2}$ gerada por meio da hibridação artificial entre os genótipos URPEL 15 (R) x UFRGS 7 (S), segregou na proporção de três plântulas resistentes para uma suscetível (3:1), conforme o esperado para tal cenário $\left(\chi^{2}=0,13\right.$ e $\left.\mathrm{P}=0,95-0,90\right)$. Entretanto, a resistência do genótipo UPF 16 ao isolado 1 é determinada por apenas um gene recessivo, uma vez que as plântulas $\mathrm{F}_{2}$ obtidas por meio do cruzamento entre os cultivares UPF 16 (R) x UFRGS 7 (S), segregaram na proporção esperada para tal cenário, uma plântula resistente para cada três suscetíveis (1:3), $\left(\chi^{2}=0,65\right.$ e $\left.\mathrm{P}=0,50-0,30\right)$. A população $\mathrm{F}_{2}$, obtida por meio da hibridação dos dois genótipos resistentes ao isolado 1, URPEL 15 (R) x UPF 16 (R), confirmaram os resultados obtidos acima, e evidenciaram que os genes que conferem resistência ao isolado 1 nos genótipos URPEL 15 e UPF 16, são diferentes e segregam independentemente, uma vez que a população $F_{2}$ gerada por meio da hibridação URPEL 15 (R) x UPF 16 (R), segregou na proporção esperada segundo tal hipótese, ou seja, 13 plântulas resistentes para cada três plântulas suscetíveis (13:3), $\left(\chi^{2}=0,87\right.$ e $\left.\mathrm{P}=0,50-0,30\right)$. Desta forma, o genótipo da constituição genética URPEL 15 para estes genes de resistência pode ser representado como sendo $\mathrm{AABB}$, com a presença de dois alelos dominantes de resistência no loco 1 (loco de resistência da URPEL 15) e presença do dois alelos dominantes de suscetibilidade para o loco 2 (loco de resistência da UPF 16); enquanto o genótipo para resistência da cultivar UPF 16 pode ser representado como sendo aabb, ou seja, ausência do alelo dominante de resistência no loco 1 (loco da resistência da URPEL 15) e presença de dois alelos recessivos de resistência no loco 2 (loco de resistência da UPF 16). Uma vez que, a reação de resistência é o efeito da interação entre o produto do gene de resistência do hospedeiro (normalmente dominante) e o produto do gene de avirulência do patógeno (normalmente dominante) como demonstrado por FLOR (1956), é possível fazer inferência a respeito do genótipo do isolado 1. Desta forma, o isolado 1 pode ser representado com o genótipo (A_bb), ou seja, apresentando pelo menos um alelo de avirulência dominante complementar ao loco de resistência do genótipo URPEL 15 e alelos complementares recessivos de avirulência ao loco de resistência da cultivar UPF 16 (Tabela 3). Entretanto, cabe ressaltar que não foram realizados cruzamentos entre isolados do patógeno, para comprovar a ação gênica dos genes de virulência e avirulência dos isolados, e que tal inferência baseia-se na teoria proposta por FLOR (1956).

A inoculação do isolado 2, sobre os cruzamentos URPEL 15 (R) x UFRGS 7 (S), UPF 18 (R) x UFRGS 7 (S) e URPEL 15 (R) x UPF 18 (R), revelou um cenário semelhante ao apresentado pelo isolado 1 (Tabela 2). Ou seja, os resultados apontaram que a resistência do genótipo URPEL 15 ao isolado 2 é determinada por apenas um gene dominante, uma vez que a população $F_{2}$ gerada por meio da hibridação artificial entre os genótipos URPEL 15 (R) x UFRGS 7 (S), segregou na proporção de 3 plântulas resistentes para uma suscetível (3:1), conforme o esperado para tal cenário $\left(\chi^{2}=0,13\right.$ e $\left.\mathrm{P}=0,95-0,90\right)$. Entretanto, a resistência do genótipo UPF 18 ao isolado 2 é determinada por apenas um gene recessivo, uma vez que as plântulas $\mathrm{F}_{2}$ obtidas por meio do cruzamento entre os cultivares UPF 18 (R) x UFRGS 7 (S), 
Tabela 3 - Segregação para resistência $(\mathrm{R})$ e suscetibilidade $(\mathrm{S})$ em progênies $\mathrm{F}_{2}$ de 8 cruzamentos de genótipos de aveia a três isolados de Puccinia coronata f. sp. avenae (1, 2 e 3). FAEM/UFPel, 2005.

\begin{tabular}{|c|c|c|c|c|c|c|}
\hline \multirow{2}{*}{ Cruzamento } & \multirow{2}{*}{ Isolado } & \multicolumn{2}{|c|}{$\mathrm{N}^{\mathrm{o}}$ de plântulas $\left(\mathrm{F}_{2}\right)$} & \multirow{2}{*}{$\begin{array}{c}\text { Segregação } \\
\text { esperada (R:S) }\end{array}$} & \multirow{2}{*}{$\chi^{2}$} & \multirow{2}{*}{$\mathrm{P}^{*}$} \\
\hline & & $\mathrm{R}$ & $\mathrm{S}$ & & & \\
\hline URPEL 15 (R) X UFRGS 7 (S) & 1 & 230 & 73 & $3: 1$ & 0,13 & $0,95-0,90$ \\
\hline UPF 16 (R) X UFRGS 7 (S) & 1 & 87 & 236 & $1: 3$ & 0,65 & $0,50-0,30$ \\
\hline URPEL 15 (R) X UPF 16 (R) & 1 & 227 & 45 & $13: 3$ & 0,87 & $0,50-0,30$ \\
\hline URPEL 15 (R) X UFRGS 7 (S) & 2 & 236 & 75 & $3: 1$ & 0,13 & $0,95-0,90$ \\
\hline UPF 18 (R) X UFRGS 7 (S) & 2 & 80 & 217 & $1: 3$ & 0,59 & $0,50-0,30$ \\
\hline URPEL 15 (R) X UPF 18 (R) & 2 & 240 & 65 & $13: 3$ & 1,31 & $0,30-0,20$ \\
\hline URPEL 15 (R) X UFRGS 7 (S) & 3 & 222 & 19 & $15: 1$ & 1,10 & $0,30-0,20$ \\
\hline URPEL 15 (R) X UPF 18 (S) & 3 & 280 & 15 & $15: 1$ & 0,68 & $0,50-0,30$ \\
\hline
\end{tabular}

${ }^{*}=$ Probabilidade para o ajuste entre a proporção esperada e a observada, pelo teste do $\chi^{2}$, sendo o nível de significância P $<0,05$.

segregaram na proporção esperada para tal cenário, uma plântula resistente para cada três suscetíveis (1:3), $\left(\chi^{2}=0,59\right.$ e $\left.\mathrm{P}=0,50-0,30\right)$. A população $\mathrm{F}_{2}$, obtida por meio da hibridação dos dois genótipos resistentes ao isolado 2, URPEL 15 (R) x UPF 18 (R), confirmaram os resultados obtidos acima, e evidenciaram que os genes que conferem resistência ao isolado 2 nos genótipos URPEL 15 e UPF 18, são diferentes e segregam independentemente, uma vez que a população $F_{2}$ gerada por meio da hibridação URPEL 15 (R) x UPF 18 (R), segregou na proporção esperada segundo tal hipótese, ou seja, 13 plântulas resistentes para cada três plântulas suscetíveis (13:3), $\left(\chi^{2}=1,31\right.$ e $\left.\mathrm{P}=0,30-0,20\right)$. Desta forma, o genótipo da constituição genética URPEL 15 para estes genes de resistência pode ser representado como sendo AABB, com a presença de dois alelos dominantes de resistência no loco 1 (loco de resistência da URPEL 15) e presença de dois alelos dominantes de suscetibilidade para o loco 2 (loco de resistência da UPF 18); enquanto que o genótipo para resistência da cultivar UPF 18 pode ser representado como sendo aabb, ou seja, ausência do alelo dominante de resistência no loco 1 (loco da resistência da URPEL 15) e presença de dois alelos recessivos de resistência no loco 2 (loco de resistência da UPF 18). Os resultados permitem também inferências a respeito do genótipo do isolado 2, desta forma este pode ser representado com o genótipo (A_bb), apresentando pelo menos um alelo de avirulência dominante complementar ao loco de resistência do genótipo URPEL 15 e alelos complementares recessivos de avirulência ao loco de resistência da cultivar UPF 18 (Tabela 3). Entretanto, cabe ressaltar que não foram realizados cruzamentos entre isolados do patógeno, para comprovar a ação gênica dos genes de virulência e avirulência dos isolados, e que tal inferência baseia-se na teoria proposta por FLOR (1956).
Os resultados obtidos por meio da inoculação dos isolados 1 e 2 sobre as plântulas $F_{2}$, evidenciaram um fato que ainda não havia sido relatado para a cultura da aveia, ou seja, a ocorrência de genes recessivos de resistência à ferrugem da folha, uma vez que CRUZ et al. (2001) relataram que a resistência à ferrugem da folha é de herança simples e oligogênica, e condicionada por um alelo dominante no genótipo UFRGS 881920 e por dois alelos dominantes de genes complementares no genótipo UFRGS 15. HARDER et al. (1995) determinaram que a resistência à ferrugem da folha na seleção X1588-2 é conferida por um gene designado no trabalho de $P c 95$. Entretanto a resistência conferida por este gene não é efetiva contra um grande número de biótipos de $\boldsymbol{P}$. coronata, para que seja considerada um boa fonte de resistência ao fungo. CHONG \& BROWN (1996) mostraram que a resistência à ferrugem da folha existente no acesso de aveia MG 85039 é determinada por dois genes complementares dominantes e que a existente no acesso MG 685181 é determinada por um único gene dominante, sendo que este gene tem mostrado grande utilidade como fonte de resistência no Canadá é foi designado $P c 96$. Em um estudo desenvolvido no Canadá, foi observado que a cultivar Dumont apresenta um terceiro gene de resistência à ferrugem da folha, uma vez que anteriormente já se sabia que a cultivar possuía os genes de resistência designados de $P c 38$ e $P c 39$, o terceiro gene detectado foi denominado de $P c \mathrm{x}$ e se mostrou ligado ao gene de resistência à ferrugem do colmo $P g 9$ (CHONG et al. 1994). Entretanto em trigo, FENG et al. (2004) relataram a ocorrência de genes de resistência recessivos ao fungo Stagonospora nodorum, em genótipos de trigo.

A inoculação do isolado 3 sobre os cruzamentos URPEL 15 (R) x UFRGS 7 (S) e URPEL 15 (R) x UPF 18 (S), revelou que a resistência do genótipo 
URPEL 15 ao isolado 3 é determinada por dois genes dominantes e que segregam independentemente, uma vez que ambas populações $F_{2}$ segregaram na proporção esperada para tal cenário, ou seja, 15 plantas resistentes para cada planta suscetível $(15: 1)$, para a população URPEL 15 (R) x UFRGS $7\left(\mathrm{~S} ; \chi^{2}=1,10\right.$ e P $\left.=0,30-0,20\right)$ e para a população URPEL $15(\mathrm{R})$ x UPF $18\left(\mathrm{~S} ; \chi^{2}=0,68 \mathrm{e}\right.$ $\mathrm{P}=0,50-0,30)$ como mostra a Tabela 2. Desta forma, o genótipo da constituição genética URPEL 15 para estes genes de resistência pode ser representado como sendo AABB, com a presença de dois alelos dominantes de resistência para cada loco; enquanto que os genótipos dos cultivares UPF 18 e UFRGS 7 podem ser representados como sendo aabb, ou seja, ausência do alelo dominante de resistência em ambos os locos. Os resultados permitem também inferências a respeito do genótipo do isolado 3 , desta forma este pode ser representado com o genótipo (A_B_), evidenciando pelo menos um alelo de avirulência dominante em cada loco complementar ao locos de resistência do genótipo URPEL 15 (Tabela 3). Entretanto, cabe ressaltar que não foram realizados cruzamentos entre isolados do patógeno, para comprovar a ação gênica dos genes de virulência e avirulência dos isolados, e que tal inferência baseia-se na teoria proposta por FLOR (1956).

Apesar de o genótipo URPEL 15 ter sido resistente aos três isolados estudados e apresentar pelo menos um loco de resistência dominante para cada isolado, os resultados não permitem determinar de maneira precisa se se trata de um mesmo gene ou de diferentes genes. O presente estudo foi conduzido em casa de vegetação com base na resistência de plântulas, por este tipo de estudo permitir a avaliação de grandes populações segregando para resistência, sob uma pressão uniforme da moléstia, o que é praticamente impossível de ser realizado a campo, em planta adulta. Esta forma de experimento é a mais indicada para a identificação de genes maiores em trabalhos genéticos, em função da grande pressão de seleção imposta, entretanto, esta abordagem não garante que a resistência evidenciada sobre a condição de plântula será efetiva a campo sobre planta adulta. Desta forma, os genes identificados, no presente estudo, devem ser efetivos na fase de plântulas, mesmo a campo, e assim diminuírem os níveis iniciais de infecção, retardando, assim, o início da doença. Programas de melhoramento que venham a aplicar a combinação entre resistência em plântulas seguida pela seleção para altos níveis de resistência a campo, podem combinar a resistência determinada por genes maiores com a determinada por genes menores e desta forma obterem a tão almejada resistência durável.
Apesar dos avanços alcançados com a realização deste trabalho, são necessários estudos mais aprofundados, utilizando novas fontes de resistência e mais isolados, para que desta forma, seja gerado um volume maior de informações e seja obtido um avanço ainda mais expressivo no sentido da compreensão da complexa interação entre a aveia e o fungo Puccinia coronata f. sp. avenae Fraser \& Led.

\section{CONCLUSÃO}

A resistência a Puccinia coronata f. sp. avenae Fraser \& Led., em alguns genótipos desenvolvidos e adaptados às condições do Sul do Brasil, têm herança simples, condicionada por um ou dois genes, que podem ser dominantes ou recessivos e que segregam de forma independente.

\section{AGRADECIMENTOS}

Os autores agradecem à FAPERGS, ao CNPq e à CAPES pelos auxílios recebidos e bolsas de pós-graduação e produtividade em pesquisa. Também à Embrapa Trigo de Passo Fundo por ter permitido e viabilizado a realização do trabalho em suas dependências.

\section{REFERÊNCIAS}

AGRIOS, G. Plant pathology. San Diego: Academic Press, 1988, 803p.

BENIN, G. et al. Adaptabilidade e estabilidade em aveia em ambientes estratificados. Ciência Rural, Santa Maria, v.35, n.2, p.295-302, 2005 .

BROWN, J.K.M; HOVMOLLER, M.S. Aerial dispersal of pathogens on the global and continental scales and its impact on plant disease. Science, Washington, v.26, n.297, p.537541, 2002 (n.5581).

CHONG, J.; BROWN, P.D. Genetics of resistance to Puccinia coronata f. sp. avenea in two Avenae sativa accessions. Canadian Journal of Plant Pathology, Guelph, v.18, n.3, p.286-292, 1996.

CHONG, J. et al. A north american system of nomenclature for Puccinia coronata f. sp. avenae. Plant Disease, Saint Paul, v.84, n.5, p.580-585, 2000.

CHONG, J. et al. Identification of stem rust resistance gene $P g 9$ and its association with crow rust resistance and endosperm proteins in "Dumont" oat. Genome, Winnipeg, v.37, n.3, p.440-447, 1994.

CHONG, J.; KOLMER, J.A. Distribution and virulence of Puccinia coronata f. sp. Avenae in Canada in 1992. Canadian Journal of Plant Pathology, Guelph, v.16, n.1, p.64-67, 1993.

CRUZ, R.P. et al. Genética da resistência à ferrugem-da-folha em aveia. Pesquisa Agropecuária Brasileira, Brasília, v.36, n.9, p.1127-1132, 2001 .

Ciência Rural, v.36, n.1, jan-fev, 2006. 
DOEHLERT, D.C. et al. Genotypic and environmental effects on grain yield and quality of oat grown in North Dakota. Crop Science, Madison, v.41, n.4, p.1066-1072, 2001.

FEDERIZZI, L.C.; STUTHMAN, D. Porque genes maiores para resistência à ferrugem da folha têm pouca durabilidade no Brasil. In: REUNIÃO DA COMISSÃO BRASILEIRA DE PESQUISA DE AVEIA, 18., 1998, Londrina. Resumos... Londrina: IAPAR, 1998. p.1-2.

FENG, J. et al. Genetics of resistance to Stagonospora nodorum blotch of hexaploid wheat. Crop Science, Madison, v.44, n.6, p.2043-2048, 2004.

FLOR, H.H. The complementary genetic systems in flax and flax rust. Advances Genetics, San Diego, v.8, n.1, p.29-54, 1956

HARDER, D.E. et al. Stem and crow rust resistance in the Wisconsin oat selection X1588-2. Crop Science, Madison, v.35, n.4, p.1011-1015, 1995.

HARDER, D.E.; HABER, S. Oat diseases and pathologic techniques. In: MARSHALL, H.G.; SORRELLS, M.E. (Eds). Oat science and technology. Madison: American Society of Agronomy, 1992. p.307-326.
KOLMER, J.A.; CHONG, J. Distribution of virulence in two populations of Puccinia coronata f. sp. Avenae in Canada Canadian Journal of Botany, Ottawa, v.71, n.7, p.946950, 1993.

LORENCETTI, C. et al. Implicações da aplicação de fungicida nos parâmetros de adaptabilidade e estabilidade de rendimento de grãos em aveia branca. Ciência Rural, Santa Maria, v.34, n.3, p.693-700, 2004.

PARLEVLIET, J.E. Present consepts in breeding for disease resistance. Fitopatologia Brasileira, Brasília, v.22, n.1, p.7$15,1997$.

SIMONS, M.D.; MURPHY, H.C. Oat diseases. In: COFFMAN, A.A. (Ed.). Oats and oat improvement. Madison: American Society of Agronomy, 1961. p.330390 .

VIEIRA, E.A. Genética da interação: Puccinia coronata $\mathbf{f}$. sp. Avenae $\mathbf{x}$ Aveia branca (Avena sativa). 2005. 96f. Tese (Doutorado em Fitomelhoramento) - Universidade Federal de Pelotas.

ZIMMER, D.E. et al. Matations for virulence I Puccinia coronata. Phytopathology, Saint Paul, v.53, n.2, p.171-176, 1963. 